\title{
Meaningful characteristics of students life strategies
}

\author{
Marianna Gorbatova ${ }^{1}$, Marina Bilan ${ }^{1},{ }^{*}$ \\ ${ }^{1}$ Kemerovo State University, Kemerovo, Russia \\ *Email: Ima_05-80@mail.ru
}

\begin{abstract}
The dynamics of changes in recent decades have led to the transformation of society's value system, the breaking of social stereotypes, and, consequently, the complication of the socialisation processes of young people and building their life strategy. The purpose of the study is to describe the meaningful characteristics of students life strategies, depending on the study profile.

Life strategies are considered as a central element in the ability of a person to build his own life, develop and improve. Based on the study of value and life-meaning orientations (150 students of five universities of different training profiles), the current level of formation and type of life strategy was determined; the content characteristics of life strategies were studied using content analysis of future autobiographies and questionnaires.

According to the results of an empirical study, it is concluded that students who have associated their choice with professions such as "man-technique" and "man-nature" are dominated by a receptive life strategy; the selection of students in specialities such as "man-artistic image" is focused on the strategy of life creation; the strategy of lifebuilding is characteristic of students studying professions such as "man-man".

The discovered patterns allow us to approach the training of young specialists in more detail, in particular, based on adjusting or developing the principles of training and creating conditions for the adequate opportunity in building an individual life strategy.
\end{abstract}

Keywords: Life strategy, Future image, Value orientations, Life meaningfulness, Study profile, University students.

\section{INTRODUCTION}

Postmodern changes affect various spheres of personal relationships both at the socio-cultural and everyday levels. The dynamics of changes in recent decades have led to the transformation of society's value system and the complication of the socialisation processes of young people. The analysis of the regulation of social behaviour from the perspective of the life strategy of the individual is the most critical problem of modern reality. The life strategy of the individual assumes a purposeful organisation of his life path based on personal values [1, 2]. Domestic researchers consider life strategies from the positions of various approaches: subjective, situational, system-functional, existentialhumanistic, spatial-temporal, narrative, etc. [1-6]. Psychological patterns of the development of valuable components of life strategies of the individual are revealed in the structural-dynamic model of life values of M.S. Yanitskiy [7].

Foreign researchers focus on script and narrative analysis of the life strategies of the individual [8-10]. In addition, life strategies are studied within the framework of various self-determination theories [11]. At the same time, domestic researchers note that a significant part of young people does not have a clear image of the future, a goal in life, the formation of a life perspective causes substantial difficulties, which causes constant interest in this problem and its relevance $[3,4,5,7]$.

\section{RESEARCH METHODS AND ORGANISATION}

The empirical base of the study conducted in 20152017 was made up of students from five universities in Kemerovo. The total sample size is 150 people, the 
average age of respondents is 22 full years. The sample population is representative by age and gender (Table 1).

To achieve the purpose of the study - to identify and describe the meaningful characteristics of the life strategies of students, we used the following methods: life orientations by D.A. Leontiev (LO); M. Rokich's value orientations; methodology for the study of life strategies of the individual by M.O. Mdivani and P.B. Kodess [6]; the autobiography of the future by G. Allport and J. Gillespie; questionnaire survey. Based on the classification of E.A. Klimov [12], the respondents were divided into groups, depending on the type of future profession:

- "man-technique" (KuzSTU and KemTIFI respondents studying in technical specialities);

- "man-nature" (respondents of the agricultural faculty of the KSAI);

- "man is an artistic image" (KemSIC respondents);

- "man-man" (KemSU respondents studying in the humanities).

\section{RESULTS DISCUSSION}

A comparative analysis of the study results on all methods revealed the specifics of the formation of life strategies among students of a particular university. The indicators identified by the LO methodology give grounds to assert that the level of life meaningfulness among students of all universities is relatively high. At the same time, students of technical universities have the best indicators (the meaningfulness indicator is 105.3). According to this scale, we obtained significant differences between the average values of KuzSTU students and KSAI students $(\mathrm{p}=0.002)$, KuzSTU and KemSIC $(p=0.045)$, KuzSTU and KemSU ( $p=0.025)$. This demonstrates that the ability to comprehend the life process, individual characteristics, and consciousness capabilities in students who have chosen a profession such as "man-technique" manifests better than in other university students. Similar data were obtained by us earlier among already working representatives of professional groups (teachers, miners, etc.) $[2,13]$.

The highest indicators on the scales of "life goals" (average volume of the category - 31.6), "process of life" (average volume of the category - 31.6) and "locus of control - life" (average volume of the category - 30.3) were also found in respondents studying in technical specialities. Revealed significant differences on the scale of "purpose in life" between the average values of KuzSTU students and students KSAI $(p=0,007)$, KuzSTU and KemSU ( $\mathrm{p}=0.0001)$; on a scale of "life process" between the average values of KuzSTU students and KSAI students $(\mathrm{p}=0,007)$, KuzSTU and KemSU ( $p=$ about 0.0006$)$; a scale of "locus of control - life" between the average values of KuzSTU students and KSAI students $(p=0,007)$, KuzSTU and KemSIC $(\mathrm{p}=0,0001), \mathrm{KuzSTU}$ and KemSU ( $\mathrm{p}=0.011)$.

The data obtained indicate that students of KuzSTU formulate such goals that can give meaning to their lives and a temporary perspective in comparison with students of other educational institutions. In addition, we can talk about a greater degree of confidence of KuzSTU students that life is subject to conscious control, and the person himself is responsible for the life decisions made and implemented.

In turn, KemSU students are more focused (in comparison with students of other universities) on the "result of life" (the average volume of the category is 28.8), significant differences on this scale were obtained between the average values of KemSU and KemTIFI students $(p=0.008)$, KemSU and KSAI $(p=0.019)$. I.e. KemSU students positively assess the life span passed and realise that this period was productive and meaningful.

KemSIC students have the highest indicators on the "locus of control - I" scale (the average volume of the category is 22.8); significant differences on this scale

Table 1. Characteristics of the sample population

\begin{tabular}{|c|c|c|c|}
\hline The name of the university of Kemerovo (abbreviation) & Total, people. & Male & Female \\
\hline $\begin{array}{l}\text { Kuzbass State Technical University named after T.F. } \\
\text { Gorbachev (KuzSTU) }\end{array}$ & 30 & 16 & 14 \\
\hline $\begin{array}{l}\text { Kemerovo Technological Institute of Food Industry } \\
\text { (KEMTIFI) }\end{array}$ & 29 & 15 & 14 \\
\hline Kemerovo State Agricultural Institute (KSAI) & 31 & 17 & 14 \\
\hline Kemerovo State Institute of Culture (KEMSIC) & 32 & 13 & 19 \\
\hline Kemerovo State University (KemSU) & 28 & 13 & 15 \\
\hline Total respondents who took part in the study & 150 & 74 & 76 \\
\hline
\end{tabular}


were obtained between the average values of KemSIC students and KemTIFI students $(\mathrm{p}=0.013), \mathrm{KemSIC}$ and KSAI ( $\mathrm{p}=0.002$ ). Obviously, KemSIC students consider themselves individuals who build their lives following their own goals and ideas.

A comparative analysis of the data on the method of "Value orientations" by M. Rokich allows us to note that for students of all universities, "health" and "love" are essential life values. However, according to M.O. Mdivani's methodology, the goal of "finding true love" is significant only for respondents of technical specialities. Consequently, concern about their health (physical and mental) and spiritual and physical intimacy with a loved one are to varying degrees significant for all respondents.

For respondents of all universities, except for KemSIC respondents, according to the method of "Value orientations" by M. Rokich, such a value as "financially secure life" is preferred, and according to the method of M.O. Mdivani, the goal of "becoming rich" is significant. Thus, the absence of material problems is of paramount importance for students of all universities, except for students of KemSIC, who consider this value less significant. These results are consistent with the "Autobiography of the Future" methodology, where all respondents described their material plans, but students of technical specialities devoted the most words to this block $(40 \%$ of the total sample). When writing autobiographies, KuzSTU students mentioned "high material well-being", described in detail their future real estate and cars, using such characteristics as: "expensive", "valuable", "three-storey cottage", "premium foreign car", "country house", "5 rooms in an apartment", which indicates a somewhat inflated level of students' claims. Respondents used the words "luxurious", "prestigious", "chic", "expensive", "valuable" when describing material values, which, in our opinion, determines the importance of the status of the item. For students of technical specialities (especially males), the size of the future housing, the brand of the car, and the level of income are also important. Significant differences in this category were obtained between the average values of students of KuzSTU and KSAI ( $p=0.0001)$, KuzSTU and KemSIC ( $p=0.0001)$, KemTIFI and KSAI ( $\mathrm{p}=0.001)$, KemTIFI and KemSIC $(\mathrm{p}=0.0001)$.

KemTIFI students in their autobiographies described "material plans" in sufficient detail but not in as much detail as KuzSTU students. At the same time, attention was also focused on the following aspects: the size of the future housing ("big apartment"), the brand of the car ("Ford car", "good Jeep"), income level ("high salary", "salary - 100,000 rubles", "bonuses", etc.). Based on this, the life strategies of students who have chosen a profession such as "man-technique" are primarily related to obtaining material benefits and ensuring the family's prosperity.
Describing material plans, KSAI students operated with a half volume of words ( $21 \%$ of the total sample), but the description itself was sufficiently elaborated but less detailed. In their autobiographies, students of the KSAI under the category of "material plans" demonstrated the following understanding of its essence: "decent earnings", "the ability to support a family", "cottage", "apartment in a good area", "car", "travel", which indicates an entirely adequate level of claims of students of this university.

KemSU students are characterised by a detailed but vague description of the "material plans" category (28\% of words from the total sample). The respondents' answers often use the following definitions: "very high income", "wealthy person", "rich", "several sources of income", "I don't deny myself anything", "beautiful country house", "large apartment", "two expensive cars", "beautiful car", "high earnings", "high-paying job with a flexible schedule". Respondents do not seek to detail their future financial situation, describing it through general characteristics.

KemSIC students deserve special attention, for whom the material condition does not play a significant role in life. They do not choose this value as their preferred one, pay little attention (compared to students of other universities) to the description of this category in autobiographies (11\% of the total sample). In their autobiographies, they described this category through the following markers: "high earnings", "enough money", "decent income", "we live in our apartment", "let's go on vacation". The statements of these students were very vague, unprocessed. In our opinion, the students of this university are focused on other life goals; they value not material goods more, but the "beauty of the world". The study found out that students of creative specialities included the value of "beauty of nature and art" in the top five most significant, while other students rejected this value. It follows from this that the experience of beauty in nature and art turns out to be essential only for respondents who have chosen a profession such as "manan artistic image". In our opinion, this may be because KemSIC students have imaginative thinking and, probably, can be more productive creatively. Also, apparently, the choice of a profession of this type is more based on the individual's desire for self-realisation and self-improvement.

The value of "happy family life" according to the method of M. Rokich is essential only for students of KuzSTU, KSAI and KemSU, and according to the method of M.O. Mdivani, the goal of "having a good family" turns out to be significant for students of all universities. Students of all universities described the "image of the future family" category in detail when writing autobiographies. So KuzSTU students use the following characteristics: "a prosperous, successful family", "healthy children", "two children", "a friendly 
family", "a 6-year-old boy, a 10-year-old girl". The markers of this category for KemTIFI students are: "there is a wife", "a hardworking husband", "three children", "work for a wife with a flexible schedule", "wife looks after the house", "home". KSAI students in their autobiographies, describing the "the image of a future family" category, used such markers as "a family of 5 people", "a housewife", "a child goes to kindergarten", "a 5 years old boy", "two children in the family", "the husband works as a director of the company", "family business". When describing the category "family" in autobiographies, KemSIC students used emotionally coloured vocabulary: "successful marriage", "happy family", "good family relations", "we all love each other". KemSU students describe the family, in fact completely avoiding specifics and applying the following characteristics: "beautiful", "happy", "friendly", "caring spouse", "ideal wife", "my husband and I have common interests", "we all spend leisure time together".

KemSIC and KemSU students consider the value of "having good and loyal friends" to be preferred, which is not significant for respondents from other universities.

"Public recognition" turns out to be an unimportant value for students of all universities, except for KemSIC students, which is consistent with the methodology of "Research of life strategies" by M. O. Mdivani, where the goal of "becoming famous" is essential only for students of creative specialities. Consequently, only students who choose a profession like "a person is an artistic image" consider it necessary to respect the people around them, the team and colleagues at work. Probably, they are more focused on creative activity than others, which is addressed to the viewer (listener, reader, etc.) and is often evaluated by other people.

Students of all universities associate the values listed above with "responsibility", i.e. awareness of a sense of duty and the ability to keep their word. Earlier in our publications, we noted that an important characteristic that directly affects the effectiveness of a life strategy is precisely responsibility $[2,13]$. Students of all universities, except KemSU students, note the importance of "good manners" to achieve their goals, which implies the presence of good manners, the ability to behave according to cultural norms. Students of technical specialities noted such a quality as "honesty", i.e. truthfulness and sincerity are a way to achieve their goals.

Rejected values for respondents of all universities are "intransigence to shortcomings in themselves and others" and "tolerance". Young people easily relate to the shortcomings of both their own and other people; simultaneously, they demonstrate a low degree of tolerance towards the views and opinions of other people and the ability to forgive their mistakes and misconceptions.
The content analysis results of the respondents autobiographies allowed us to state the following features of the future image. The total volume of autobiographies differed significantly from university to university. Thus, the total volume of autobiographies of KuzSTU students amounted to 443 words, KemTIFI students - 392 words, KSAI students - 306 words, KemSIC - 368 words. At the same time, 2 respondents could not write anything about their plans for the future; KemSU students amounted to 695 words.

Thus, KemSU students as a whole described their future in more detail than students of other universities. This may be because they study the humanities, which contributes to a better command of oral and written speech.

For all respondents, the significant categories of the image of the future are: "family", "work", "material plans", "I am an image". Describing their future, respondents of all groups identify a certain general minimum, which includes: family, work, a good salary, an apartment and a car. The analysis of the respondents' writing allowed us to present the differences in the image of the future in the following categories: "the image of the future family", "professional future", "material plans", and "general "self-image" and personal future".

Students of all universities described the family, but students of humanities devoted the most words to the "image of the future family" category (36\% of the total sample), significant differences in this category were obtained between the average values of KemSU and KSAI students $(\mathrm{p}=0.007)$, KemSU and KemSIC $(\mathrm{p}=0.045)$. Respondents studying in the humanities used the following characteristics in the description: "beautiful", "happy", "friendly", "warm relationship", "beloved and caring husband", "husband looks after beautifully even after the wedding", "beautiful kids", "several children", "I'm sitting at home with two beautiful kids". The characteristics, in our opinion, are mainly emotional; the descriptions of these students are not structured and not specified.

Students studying in technical specialities $(27 \%$ of the total sample) paid fewer words to the description of the future family. In their autobiographies, KuzSTU and KemTIFI students noted that the components of family life are: official registration of marriage, caring and loving spouse, children, a favourable climate in the family (support and mutual understanding). The category "the image of a future family" was described by students through the following characteristics: "there is a family", "get married", "in 2022 I will get married", "beautiful and faithful wife", "there is a wife", "hardworking husband", "wife works as a doctor", "housewife wife", "husband earns enough", "wife sits with children", "faithful husband", "good wife", "understanding wife", "rest with family", "7 years old boy and 3 years old girl", "two boys", "two children with a difference of one year", 
"healthy children", "obedient children", "good atmosphere in the family", "rarely quarrel", "prosperous, successful family". Descriptions of students of technical universities are quite specific and detailed.

When describing the "image of the future family", KemSIC students used fewer words $(20 \%$ of the total sample) and the following markers: "successful marriage", "happy family", "everything is good in the family", "we live happily", "bright family everyday life", "two wonderful children and a beloved husband".

The least number of words to "the image of a future family" block were devoted by KSAI students (17\% of the total sample). In their autobiographies, they described this category through the following markers: "a family of 5 people", "a child goes to kindergarten", "a 6 years old boy, a 10 years old girl", "we are going to give birth to a second child", "a housewife wife", "a kind husband", "a faithful and obedient wife", "a friendly family", "warm relations in the family", "a wife works in personnel", "a husband is a director of a firm", "a small business". The descriptions are well developed.

Students of all universities described their professional future. Still, students of humanities devoted the most words to this block ( $32 \%$ of the total sample), they used the following characteristics: "work is close to home", "work is close", "close-knit, friendly team", "respect at work", "interesting colleagues". In describing their professional future, in our opinion, students use very abstract characteristics that are not directly related to professional activity but describe social contacts at work and the advantages of geographical location.

$30 \%$ of the words from the total sample were used when describing future work by students studying in technical specialities. Significant differences in this category were obtained between the average values of KuzSTU and KSAI students $(\mathrm{p}=0.0008)$, KemTIFI and KSAII ( $p=0.0006)$, KemTIFI and KemSIC ( $p=0.044)$. In their autobiographies, students of technical specialities demonstrated the following understanding of the essence of the category "professional plans": acquisition of knowledge and skills by profession, employment by occupation, improvement in the profession, career growth, honour and respect in the profession, good relations in the team. Respondents noted: "work in a mine", "position of a leading engineer", "managerial position", "chief engineer", "work by profession", "head of production", "permanent job", "not necessarily a managerial position". Descriptions of students of technical universities are specific; they are pretty straightforward and detailed. Respondents describe this category as really assessing their capabilities.

KemSIC students in the description of the "professional future" used fewer words (20\% of the total sample) and the following tokens: "favourite activity", "a fascinating work," "fun activity", "good job", "my business", "work, dreamed about, and work with a flexible schedule", "work the head" - plans for his professional future is not specified and poorly developed.

The smallest number of words in the "professional future" block is among students of KSAI (18\% of the total sample). The following markers are presented in the autobiographies: "a job that I like", "an interesting job", "a position of a manager", "an 8-hour working day", "a gradual increase in the career ladder", "a desire to move up (in my career)", "a work schedule that suits me", "a boring job".

Students of all universities described "a common selfimage and personal future". Students of creative specialities devoted the most words to this block (38\% of the total sample). Significant differences in this category were obtained between the average values of KemSIC students and KSAI students $(\mathrm{p}=0.0003)$. Students studying at KemSIC focused on such aspects as "lucky", "I look amazing", "successful", "self-confident", "cheerful", "happy moments of life", "I travel a lot to different beautiful countries", "we often go abroad, travel".

$31 \%$ of the words from the total sample when describing their "I-image" were used by students who chose a profession like "man-man". Also, significant differences in this category were obtained between the average values of KemSU and KSAI students ( $p=0.013$ ). In the description of this category, KemSU students mainly use emotional characteristics: "happy", "successful", "beautiful", "self-confident", "unforgettable travels", "interesting hobby". At the same time, the statements of individual respondents are more specific: "I'm learning to knit," "I'm learning Chinese," "I'm going to Canada," "I'm learning to play the piano."

KuzSTU and KemTIFI students used $21 \%$ of the words from the total sample and the following markers: "everything will be fine", "happy", "we love to travel", "we always take our sons on all trips", "I look great", "my wife and I fly abroad to eat exotic fruits, swim in the sea and to travel to historical places", "our life is full of happy moments", "we are happy together", "we have a family vacation abroad in the summer".

The least number of words in the block "general "selfimage" and personal future" were used by students who chose a profession like "man-nature" (10\% of the total sample). The markers of this category were: "successful", "cheerful", "my life was a success", "everything is fine with us", I like to sort out the car on weekends", "we go on vacation to the sea", "we often fly to hot countries".

Based on the above, we conclude that KuzSTU students plan for the future, are focused on results, are distinguished by the ability to take control of their lives and make decisions freely. Also essential for them is to be concerned about their own physical and mental health, spiritual and physical intimacy with a loved one, the 
creation of a prosperous, happy family, a professional future, the absence of material problems, good manners and the presence of good manners, the ability to behave following the norms of the culture of behaviour, honesty and sincerity.

KemTIFI students demonstrate such life priorities as concern for their health, emotional and physical intimacy with a loved one, material prosperity, creating a prosperous, happy family, professional future, and responsibility, sense of duty, good manners, honesty and sincerity.

Significant life priorities for KSAI students are maintaining their health (physical and mental), intimacy with a loved one (physical and spiritual), material prosperity, a happy family life, as well as responsibility, a sense of duty, the ability to keep their word, good manners, and the presence of good manners.

For KemSIC students, important life priorities are health (physical and mental), intimacy with a loved one (physical and spiritual), the beauty of nature and art, the presence of good and loyal friends, the opportunity to engage in creativity, a "common" self-image and personal future," i.e. plans related to self-development, as well as responsibility, a sense of duty, the ability to keep your word, good manners, high demands on life and high claims.

KemSU students have a significant focus on the result of life, i.e. on satisfaction with self-realisation. For them, the following are essential: health (physical and mental), intimacy with a loved one (physical and spiritual), material prosperity, a happy family life, having good and loyal friends, a professional future, a "common "selfimage" and a personal future," i.e. plans related to selfdevelopment, as well as responsibility, a sense of duty, the ability to keep their word.

\section{CONCLUSIONS}

Based on the study results of the university students life strategies, the following conclusions can be drawn:

1. In the minds of young people studying in technical specialities, the categories of "future family image", "material plans", and "professional future" are well worked out, schematised. Plans for the future are pretty specific and more adequate, although respondents have an inflated level of claims among KuzSTU students.

The content characteristics of the life strategies of students of "natural science" areas of training are well developed, outlined, plans for the future are quite specific, the level of claims of these students is not overstated. Respondents of this group are more focused on family and material values and the health of loved ones.
The life strategies of students of creative directions are poorly developed and almost not specified, and their statements have a more emotional character than those of students of technical specialities. Accordingly, students of creative specialities demonstrate an excellent life orientation towards goals and values related to communication, the search for social contacts, their pleasure and self-realisation.

Students of humanities represent their future in more detail, but the number of words in their autobiographies is not proportional to the quality of their study. Students of these specialities do not prescribe specific plans, write more abstractly, vaguely, use many synonyms; their life plans are more emotional than the plans of technical students.

2. There are significant differences in the content characteristics of the life strategies of students, depending on the profile of training. Training performs the most critical functions in developing personality and forming its life strategies, and its features are closely correlated with the specifics of the chosen speciality and future profession. The training programs at each faculty have their distinctive features; therefore, at the stage of preparation for professional activity, a person has an intensive development of qualities characteristic of specialists in this field of training, which undoubtedly affects the personality and its life strategies. Thus, the profile of education affects the development of personal values, professional qualities, and, consequently, the formation of a specific life strategy of students.

\section{REFERENCES}

[1] O.Yu. Pereverzina, Yu.V. Sinyagin, Notional and research discourse: problems of personal life strategies, Voprosy Psihologii 3 (2017) 149-158.

[2] M.M. Gorbatova, M.A. Ljahova, Life values examination of employus as a special stratum, Siberian journal of psychology 25 (2007) 142-147.

[3] J.V. Gaskova, I.A. Ralnikova, Life prospects in the field of professional activity for students mastering creative specialities, Siberian journal of psychology 65 (2017) 53-65. DOI: https://doi.org/10.17223/17267080/65/4

[4] E.Yu. Korjova, E.N. Volkova, O.V. Rudykhina, E.N. Tumanova, The psychology of a person as a subject of life activity and personality life span: main research results, Herzen University Journal of Humanities \& Sciences 187 (2018) 40-50.

[5] S.N. Kostromina, N.V. Grishina, E.V. Zinovyeva, N.L. Moskvicheva, Life model as a construct for studying the life scenario of personality, Psihologiya - Vestnik of Saint Petersburg University, 
Psychology 8(4) (2018) 341-357. DOI: https://doi.org/10.21638/11701/spbu16.2018.403

[6] M.O. Mdivani, P.B. Kodess, Method of personal living strategies investigation, Voprosy psihologii 4 (2006) 146-150.

[7] M.S. Yanitskiy, System of Value Orientations of Personality and Social Communities: Structural and Dynamic Model and its Application in Psychological Research and Psychological Practice, Vestnik Kemerovskogo gosudarstvennogo universiteta 22(1) (2020) 194-206. DOI: https://doi.org/10.21603/2078-8975-2020-22-1194-206

[8] L. Nota, R. Rossier, Handbook of Life Design, From Practice to Theory and From Theory to Practice (Eds.), Hogrefe Publishing, 2015.

[9] C. Vasile Self-programming as Psychological Response, Procedia Social and Behavioral Sciences 128 (2014) 82-86.

[10] S. Vazire, T.D. Wilson, Handbook of SelfKnowledge (Eds.), New York: Guilford, 2012.

[11] T. Martos, V. Sallay, Self-determination theory and the emerging fields of relationship science and niche construction theory, European Journal of Mental Health 12(1) (2017) 73-87.

[12] E.A. Klimov, T.M. Buyakas, N.N. Zotova, Difficulties and prospects of becoming a professional, Municipal education: innovations and experiment 3 (2014) 48.

[13] M. Gorbatova, A. Gorbatov, A. Pyanov, A. Levanova, Retraining professional management personnel at coal industry enterprises: the requirements of the time. E3S Web of Conferences, 3rd International Innovative Mining Symposium, IIMS 2018: Electronic edition, 2018. DOI: https://doi.org/10.1051/e3sconf/20184104031 